\title{
Polychlorinated dibenzo-p-dioxins, dibenzofurans, and dioxin-like polychlorinated biphenyls in sediments from the Yellow and Yangtze Rivers, China
}

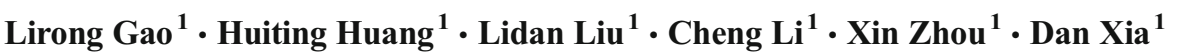

Received: 16 June 2015 / Accepted: 6 August 2015 /Published online: 19 August 2015

(C) Springer-Verlag Berlin Heidelberg 2015

\begin{abstract}
Polychlorinated dibenzodioxins and dibenzofurans $(\mathrm{PCDD} / \mathrm{Fs})$ and polychlorinated biphenyls (PCBs) are toxic environmental pollutants that are often found in sediments. The Yangtze and Yellow rivers in China are two of the largest rivers in Asia and are therefore important aquatic ecosystems; however, few studies have investigated the $\mathrm{PCDD} / \mathrm{F}$ and $\mathrm{PCB}$ content in the sediments of these rivers. Accordingly, this study was conducted to generate baseline data for future environmental risk assessments. In the present study, 26 surface sediments from the middle reaches of the Yellow and Yangtze rivers were analyzed for PCDD/Fs and dioxin-like (dl) PCBs by high-resolution gas chromatography and high-resolution mass spectrometry. The ranges of $\mathrm{PCDD} / \mathrm{F}$, dl-PCB, and WHO-TEQ content in sediments from the Yellow River were $2.1-19.8,1.11-9.9$, and $0.08-0.57 \mathrm{pg} / \mathrm{g}$ (dry weight), respectively. The ranges of PCDD/F, dl-PCB, and WHO-TEQ content in sediments from the Yangtze River were 6.1-84.9, 1.824.1 , and $0.13-0.29 \mathrm{pg} / \mathrm{g}$ (dry weight), respectively. Total organic carbon and dl-PCB contents in the Yellow River were significantly correlated (Spearman's correlation coefficient, $r=0.64, P<0.05)$. It is well known that total organic carbon plays a role in the transport and redistribution of dl-PCB. Principal component analysis indicated that $\mathrm{PCDD} / \mathrm{Fs}$ may
\end{abstract}

Responsible editor: Ester Heath

Electronic supplementary material The online version of this article (doi:10.1007/s11356-015-5175-2) contains supplementary material, which is available to authorized users.

Lirong Gao

gaolr@rcees.ac.cn

1 State Key Laboratory of Environmental Chemistry and Ecotoxicology, Research Center for Eco-Environmental Sciences, Chinese Academy of Sciences, Beijing 100085, China arise from pentachlorophenol, sodium pentachlorophenate, and atmospheric deposition, while dl-PCBs likely originate from burning of coal and wood for domestic heating. The dioxin levels in the river sediments examined in this study were relatively low. These findings advance our knowledge regarding eco-toxicity and provide useful information regarding contamination sources.

Keywords Polychlorinated dibenzo-p-dioxin and dibenzofuran - Dioxin-like polychlorinated biphenyl . Sediment · Middle reach $\cdot$ Yellow River · Yangtze River

\section{Introduction}

Polychlorinated dibenzo- $p$-dioxins and dibenzofurans (PCDD/Fs) and dioxin-like polychlorinated biphenyls (dlPCBs) are widespread environmental contaminants. Because of their adverse health effects, persistence, bioaccumulation, and ubiquitous presence in the environment (Kannan et al. 2005; Nunes et al. 2014), they are identified as unintentional persistent organic pollutants (POPs) in the Stockholm Convention. POPs can be transferred into aquatic systems via various pathways, including atmospheric deposition, industrial and domestic effluents, storm water, and spills (BuckleyGolder 1999). POPs are hydrophobic compounds that are easily integrated into the particle phase in aqueous systems, where they are ultimately deposited in the sediments by settling (Kim et al. 2009; Montuori et al. 2014). Therefore, sediments are regarded as the main aquatic reservoirs of POPs. However, sediments may also play a role as secondary contamination sources. Bound POPs in the sediments can be rereleased into the water, where they have the potential to affect aquatic organisms (Kim et al. 2009; Montuori et al. 2014). Sediments with bound POPs can pose a further threat 
to humans and wildlife via biogenic accumulation (Neamtu et al. 2009). POPs in the sediments are also known to cause adverse effects including carcinogenicity, reproductive impairment, and endocrine disruption in wildlife and humans (Van den Berg et al. 2006). Consequently, sediment is an important medium for assessing POP levels in aquatic environments.

The Yellow and Yangtze rivers, which are two of the largest freshwater rivers in China, play an important societal role. The Yellow River is the second largest river in China and one of the main water resources of North China. Because of rapid industrialization and urbanization along the river's banks, an increasingly large volume of organic-laden wastewater is discharged into the Yellow River and its tributaries (Wang et al. 2010), which has resulted in environmental stress. Although some studies have investigated organochlorine pesticides in sediments from the Yellow River (Da et al. 2013; Wang et al. 2010), there is little information available regarding the levels of PCDD/Fs and dl-PCBs in sediments from the middle reaches of the Yellow River in China. The Yangtze River originates from the Qinghai-Tibet Plateau and flows into the East China Sea, with a main stream length of over $6300 \mathrm{~km}$. Because of rapid population increases and economic growth in the regions around the river, there are numerous inputs from industrial wastewater, municipal sewage, atmospheric deposition, as well as agricultural soils containing fertilizers, pesticides, herbicides, and heavy metals (Song et al. 2010). While there have been many studies on inorganic and organic matter in sediments from the Yangtze River (Gui et al. 2012; Wen et al. 2013), few have investigated PCDD/F or PCB levels in surface sediments from the Yangtze River (Liu et al. 2003; Wen et al. 2008). PCDD/Fs and dl-PCBs have been detected in sediments from the Yellow and Yangtze estuaries (Hui et al. 2009). Because of rapid economic development along the middle reaches of these rivers, it is important to also carry out studies of these regions. Additionally, investigations of the middle reaches of the Yellow and Yangtze rivers will provide baseline data for future environmental risk assessments.

The present study was conducted to investigate the contents of PCDD/Fs and dl-PCBs in sediments from the middle reaches of the Yellow and Yangtze rivers. The distribution status of PCDD/Fs and dl-PCBs in these rivers will help identify pollution sources. Additionally, this study will provide a preliminary ecological risk assessment of the middle reaches of the rivers.

\section{Materials and methods}

\section{Sample collection}

Surface sediment samples (0-5 $\mathrm{cm}$ in depth) were collected from the middle reaches of the Yellow and Yangtze rivers
(China) using stainless steel grab samplers (Ekman Grab Sampler, Wildlife Supply Company, Yulee, FL) from October to November 2010. Sample positions were recorded with a global positioning system. Three to five sediment samples were collected at each sampling site, and all samples taken at a site were combined and homogenized before analysis.

The sampling locations are shown in Fig. 1. Thirteen sediment samples were collected in the Yellow River over approximately $200 \mathrm{~km}$, from Luoyang to Kaifeng in Henan province. The 13 sampling points in the Yangtze River were also distributed over approximately $200 \mathrm{~km}$, from Yichang to Jingzhou in Hubei province. All samples were freeze-dried, ground into powder, homogenized, and stored in amber glass bottles at $-20{ }^{\circ} \mathrm{C}$ until extraction.

\section{Extraction and cleanup}

Preparation and analysis of the samples were conducted in accordance with US EPA Method 1613B and 1668A for PCDD/Fs and dl-PCBs, respectively. Before extraction, $10 \mathrm{~g}$ of each dried sediment sample was homogenized and spiked with known amounts of ${ }^{13} \mathrm{C}_{12}$-labeled alternative internal standards (Wellington Laboratories, Guelph, Canada; ${ }^{13} \mathrm{C}$ 1613LCS and $\left.{ }^{13} \mathrm{C} 1668 \mathrm{LCS}\right) .{ }^{13} \mathrm{C}_{12}$-labeled alternative internal standards of PCDD/Fs specifically included: ${ }^{13} \mathrm{C}_{12}-2,3,7$, 8-TCDD, ${ }^{13} \mathrm{C}_{12}-1,2,3,7,8-\mathrm{PeCDD},{ }^{13} \mathrm{C}_{12}-1,2,3,4,7,8$ HxCDD, ${ }^{13} \mathrm{C}_{12}-1,2,3,6,7,8-\mathrm{HxCDD},{ }^{13} \mathrm{C}_{12}-1,2,3,4,6,7,8-$ HpCDD,${ }^{13} \mathrm{C}_{12}$-OCDD, ${ }^{13} \mathrm{C}_{12}-2,3,7,8-\mathrm{TCDF},{ }^{13} \mathrm{C}_{12}-1,2,3,7$, 8-PeCDF, ${ }^{13} \mathrm{C}_{12}-2,3,4,7,8-\mathrm{PeCDF},{ }^{13} \mathrm{C}_{12}-1,2,3,4,7,8-\mathrm{HxCDF}$, ${ }^{13} \mathrm{C}_{12}-1,2,3,6,7,8-\mathrm{HxCDF},{ }^{13} \mathrm{C}_{12}-1,2,3,7,8,9-\mathrm{HxCDF},{ }^{13} \mathrm{C}_{12^{-}}$ 2,3,4,6,7,8-HxCDF, ${ }^{13} \mathrm{C}_{12}-1,2,3,4,6,7,8-\mathrm{HpCDF}$ and ${ }^{13} \mathrm{C}_{12}-1$, 2,3,4, 7,8,9-HpCDF. Additionally, ${ }^{13} \mathrm{C}_{12}$-labeled alternative internal standards of PCBs specifically included: ${ }^{13} \mathrm{C}_{12^{-}}$ PCB-1, ${ }^{13} \mathrm{C}_{12}$-PCB-3, ${ }^{13} \mathrm{C}_{12}$-PCB-4, ${ }^{13} \mathrm{C}_{12}$-PCB-15, ${ }^{13} \mathrm{C}_{12}-$ PCB-19, ${ }^{13} \mathrm{C}_{12}-\mathrm{PCB}-37,{ }^{13} \mathrm{C}_{12}-\mathrm{PCB}-54,{ }^{13} \mathrm{C}_{12}-\mathrm{PCB}-81$, ${ }^{13} \mathrm{C}_{12}$-PCB-77, ${ }^{13} \mathrm{C}_{12}$-PCB-104, ${ }^{13} \mathrm{C}_{12}$-PCB-105, ${ }^{13} \mathrm{C}_{12}$-PCB$114,{ }^{13} \mathrm{C}_{12}$-PCB-126, ${ }^{13} \mathrm{C}_{12}$-PCB-155, ${ }^{13} \mathrm{C}_{12}$-PCB-156, ${ }^{13} \mathrm{C}_{12}-$ PCB-157, ${ }^{13} \mathrm{C}_{12}$-PCB-167, ${ }^{13} \mathrm{C}_{12}$-PCB-169, ${ }^{13} \mathrm{C}_{12}$-PCB-188, ${ }^{13} \mathrm{C}_{12}$-PCB-189, ${ }^{13} \mathrm{C}_{12}$-PCB-202, ${ }^{13} \mathrm{C}_{12}-\mathrm{PCB}-205,{ }^{13} \mathrm{C}_{12}$ PCB-206, ${ }^{13} \mathrm{C}_{12}$-PCB-208 and ${ }^{13} \mathrm{C}_{12}$-PCB-209. The sediments were then extracted in an accelerated solvent extractor (Thermo Fisher ASE 350), followed by two successive static extraction cycles using $30-40 \mathrm{~mL}$ of hexane/dichloromethane $(1: 1, v / v)$ for $15 \mathrm{~min}$ at $1.03 \times 10^{4} \mathrm{kPa}$ and $150{ }^{\circ} \mathrm{C}$.

Next, extracts were concentrated using a rotary evaporator (Heidolph, Schwabach, Germany), after which the residues were purified on an acidic silica gel column treated with $44 \%$ sulfuric acid $(30.0 \mathrm{~cm} \times 15.0 \mathrm{~mm}$ i.d. $)$ and multilayer silica columns $(30.0 \mathrm{~cm} \times 15.0 \mathrm{~mm}$ i.d. $)$. The PCDD/Fs and dl-PCBs were fractionated on a basic alumina column ( $20.0 \mathrm{~cm} \times 8.0 \mathrm{~mm}$ i.d.), then concentrated to about $20 \mu \mathrm{L}$ by rotary evaporation followed by a gentle stream of nitrogen. Samples were spiked with ${ }^{13} \mathrm{C}_{12}$-labeled injection internal 
Fig. 1 Map of the sampling sites in the middle reaches of the Yellow and Yangtze rivers
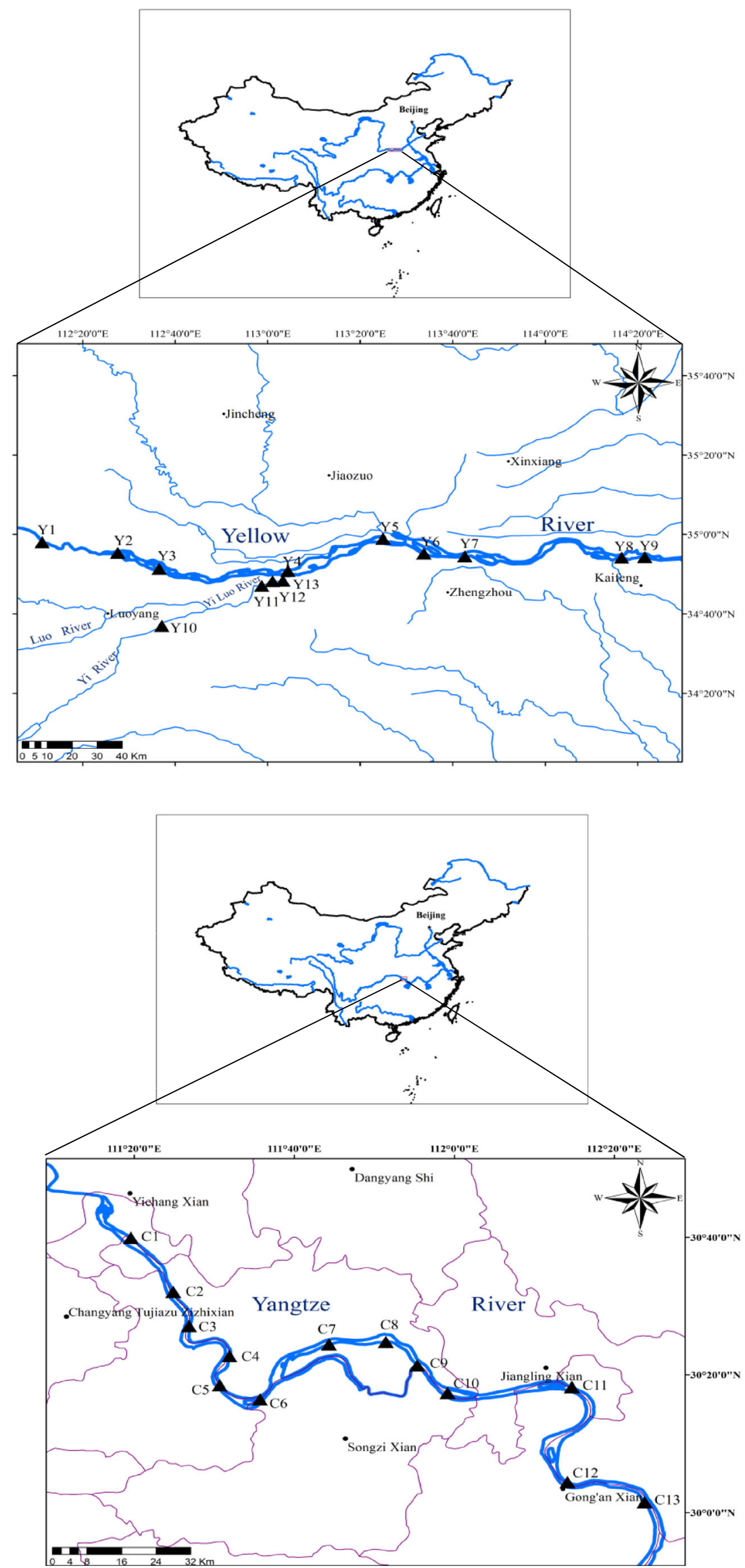
standards of PCDD/Fs $\left({ }^{13} \mathrm{C}_{12}-1,2,3,4-\mathrm{TCDD}\right.$ and ${ }^{13} \mathrm{C}_{12}-1,2,3$, 7,8,9-HxDD $)$ and PCBs $\left({ }^{13} \mathrm{C}_{12}\right.$-PCB-9, ${ }^{13} \mathrm{C}_{12}$-PCB-52, ${ }^{13} \mathrm{C}_{12^{-}}$ PCB-101, ${ }^{13} \mathrm{C}_{12}$-PCB-138 and ${ }^{13} \mathrm{C}_{12}$-PCB-194) before extraction for recovery correction. The spiked extracts were subsequently injected into a high-resolution gas chromatograph and high-resolution mass spectrometer for analysis.

\section{Instrumental analysis}

PCDD/Fs and dl-PCBs were identified and quantified on a high-resolution gas chromatograph and high-resolution mass spectrometer (AutoSpec Ultima). The HRMS (Waters, Milford, MA) was operated in positive electron ionization mode with selected ion monitoring (SIM), an ionization energy of $35 \mathrm{eV}$ and an ion source temperature of $270{ }^{\circ} \mathrm{C}$ at $R \geq 10$, 000 .

The high-resolution gas chromatography (HRGC) (Agilent 6890, Agilent Technologies, Santa Clara, CA) was equipped with a DB-5 column $(60.0 \mathrm{~m} \times 0.25 \mathrm{~mm}, 0.25 \mu \mathrm{m})$ and operated in splitless mode. The sample volume was $1 \mu \mathrm{L}$ and was injected by an auto-sampler (CTC PAL, CTC Switzerland, Zwingen, Switzerland). Helium was used as the carrier gas at a constant flow rate of $1.2 \mathrm{~mL} / \mathrm{min}$. To analyze PCDD/Fs, the following GC temperature program was used: (1) $150{ }^{\circ} \mathrm{C}$ initial isothermal hold for $3 \mathrm{~min}$, (2) increase at $20^{\circ} \mathrm{C} / \mathrm{min}$ to an isothermal hold at $230{ }^{\circ} \mathrm{C}$ for $18 \mathrm{~min}$, (3) increase at $5{ }^{\circ} \mathrm{C} / \mathrm{min}$ to an isothermal hold at $235^{\circ} \mathrm{C}$ for $10 \mathrm{~min}$, and (4) increase at $4{ }^{\circ} \mathrm{C} / \mathrm{min}$ to an isothermal hold at $320{ }^{\circ} \mathrm{C}$ for $3 \mathrm{~min}$. The temperature program used for dl-PCBs analysis was as follows: (1) $120^{\circ} \mathrm{C}$ initial isothermal hold for $1 \mathrm{~min}$, (2) increase at $30{ }^{\circ} \mathrm{C} / \mathrm{min}$ to $150{ }^{\circ} \mathrm{C}$, and (3) increase at $2.5^{\circ} \mathrm{C} / \mathrm{min}$ to an isothermal hold for $1 \mathrm{~min}$ at $300^{\circ} \mathrm{C}$.

For TOC analysis, freeze-dried and homogenized sediment samples were treated with $5 \%$ phosphoric acid to remove carbonates prior to measurement. The content of total organic carbon (TOC) in the sediment samples was analyzed using a TOC analyzer (O.I. Analyzer, Station, TX).

\section{Quality control and quality assurance}

Our laboratory participated in round $10-17$ of the international intercalibration of dioxins and dl-PCBs organized by Örebro University in Sweden, and the Biennial Global Interlaboratory Assessment on persistent organic pollutants is organized by the United Nations Environment Programme (UNEP). The results of the analyses performed in our laboratory agreed well with the median of the results produced by all of the participating laboratories around the world. A method blank and a parallel sample were analyzed with each sample batch (six samples). The recovery was obtained by calculating the ratio of the labeled cleanup standard and the labeled injection internal standard. According to ${ }^{13} \mathrm{C}_{12}$-labeled isotope internal standards, the recovery ranges of the $\mathrm{PCDD} / \mathrm{Fs}$ and $\mathrm{PCBs}$ were
$42-120$ and $70-123 \%$, respectively, which are defined as acceptable in method 1613B and 1668A. Five sediment samples of 26 sediment samples were randomly selected to conduct the parallel analysis experiment. The RSD of results was not more than $10 \%$. Field and laboratory blanks were collected with each set of samples and processed in a manner identical to the samples. The limit of detection (LOD) was defined as three times the signal/noise ratio. The LOD values determined for this study ranged from 0.02 to 0.1 and 0.03 to $0.08 \mathrm{pg} / \mathrm{g}$ for PCDD/Fs and dl-PCBs, respectively. When concentrations were below the LOD, a value of half the LOD was used to calculate the total concentrations and toxic equivalents (TEQs). No lower chlorinated congeners were detected in the blanks. Octachlorodibenzo- $p$-dioxin (OCDD) was the most prevalent congener in the blanks. The contents of target compounds in the blanks were less than $5 \%$ of the contents found in the sediment samples. Therefore, OCDD does not affect the experimental results of the sediment samples

\section{Statistical analysis}

Principal component analysis (PCA) was performed using the SPSS 22.0 statistical package (SPSS Inc., Chicago, IL, USA). The contents of congeners below the LOD were assumed to be zero. Principal components with eigenvalues greater than 1 were considered. Through factor analysis using SPSS, the data were projected into two dimensions, resulting in generation of a simpler and easier to understand data set. Additionally, potential emission data were provided to recognize the relationship between the sediment receptors and the possible emission sources through groups or cluster characters and distances in output figures. PCA was widely used to compare congenerspecific data from the large number of samples in detail to determine the possible sources of PCDD/Fs and PCBs in the samples.

\section{Results and discussion}

\section{Contamination levels of PCDD/Fs and dl-PCBs}

\section{Content of $P C D D / F s$ and dl-PCBs}

The contents of PCDD/Fs and dl-PCBs found in surface sediment samples from the middle reaches of the Yellow and Yangtze rivers in China are given in Table S1 and Table S2 (see Supplementary material). The contents of $\Sigma_{17} \mathrm{PCDD} / \mathrm{Fs}$ in the sediment samples from the Yellow River ranged from 2.10 to $19.80 \mathrm{pg} / \mathrm{g}$ dry weight (dw). These contents were much lower than those in the Yellow River estuary (2.30 $253 \mathrm{pg} / \mathrm{g} \mathrm{dw}$, August 2004) (Hui et al. 2009), which might have been due to implementation of the Stockholm Convention, or to different positions and/or different pollution 
Table 1 The PCDD/Fs and dl-PCBs (pg TEQ/g dw) in surface sediments of different regions in the world

\begin{tabular}{llll}
\hline Location & PCDD/Fs & dl-PCBs & Reference \\
\hline The middle reaches of the Yellow River & $0.08-0.55$ & $0.001-0.043$ & This study \\
The middle reaches of the Yangtze River & $0.09-0.46$ & $0.002-0.036$ & This study \\
Daliao River Basin & $0.28-29.01(7.45)$ & ND & (Zhang et al. 2008) \\
Yangtze Estuary & $0.36-0.74$ & $0.001-0.03$ & (Hui et al. 2009) \\
East River & $2.1-9.8(4.5)$ & $0.042-0.45(0.19)$ & (Ren et al. 2009) \\
Pearl River Delta & $3.1-9.5$ & ND & (Zhang et al. 2009) \\
Taihu Lake & $0.83-17.72$ & ND & (Zhang and Jiang 2005) \\
Tokyo Bay, Japan & $0.39-49$ & $0.18-3$ & (Hosomi et al. 2003) \\
Toyano lagoon, Japan & $0.49-76$ & ND & (Sakai et al. 2008) \\
Hyeongsan River, Korea & $0.38-1037$ & $0.05-3.37$ & (Koh et al. 2004) \\
Lake Maggiore, Italy & $0.1-17$ & $0.03-6$ & (Castro-Jimenez et al. 2008) \\
Nile River, Egypt & $1.8-38.1$ & $0.08-1.3$ & (El-Kady et al. 2007) \\
Northwest Mediterranean & $0.4-39.24$ & $0.03-24.75$ & ND \\
Po River, Italy & $1.3-13$ & & (Eljarrat et al. 2001) \\
\hline
\end{tabular}

$N D$ not detected

sources. PCDD/F contents in the 13 sediment samples from the Yangtze River ranged from 6.05 to $84.87 \mathrm{pg} / \mathrm{g}$ dw (mean $21.78 \mathrm{pg} / \mathrm{g} \mathrm{dw}$ ) and were about three times those in the samples from the Yellow River. The total PCDD/F contents in sediment samples from the Yangtze River were more than 10 times lower than those $(0.31$ to $51 \mathrm{pg} \mathrm{TEQ} / \mathrm{g} \mathrm{dw}$, September 2010) collected from the lower Yangtze River basin, Jiangsu, and Shanghai areas of Eastern China (Nie et al. 2013), likely because the lower Yangtze River basin contained more industrial areas than the middle reaches of the Yangtze River.

The mean content of $\Sigma_{12}$ PCBs in the 13 sediment samples from the Yellow River was $2.50 \mathrm{pg} / \mathrm{g} \mathrm{dw}$ (range 1.12-9.90 pg/ $\mathrm{g} \mathrm{dw}$ ), which was three orders of magnitude lower than the dlPCB contents (range $<$ LOD-5.98 ug/ $/ \mathrm{kg} \mathrm{dw}$, June 2004) in surface sediments from the mid- and down-stream regions of the Yellow River (He et al. 2006). The contents of $\Sigma_{12}$ PCBs in the 13 sediment samples from the Yangtze River ranged from 1.79 to $24.07 \mathrm{pg} / \mathrm{g}$ dw and were about three times higher than those in the samples from the Yellow River. Although the middle reaches of the Yellow River (Henan province) and the Yangtze River (Hubei province) are mainly agricultural, rapid development of industry has made pollution of the middle reaches of the Yangtze River more serious. The total dl-PCB contents (range 5.08-19.64 ng/g dw, October 2007) in sediments from the Yangtze River estuary and East China Sea (Yang et al. 2012) was three orders of magnitude higher than those found in the Yangtze River in the present study. Although the levels of PCDD/Fs and dl-PCBs in the Yangtze River were higher than those in the Yellow River, the levels of PCDD/Fs and dl-PCBs in both rivers were generally low compared with Canadian environmental quality guidelines and the contents in other rivers in China and other countries.

\section{Toxic equivalency factors of $P C D D / F$ and $d l-P C B$ contents}

The World Health Organization toxic equivalency factors (WHO-TEFs 2005) (Van den Berg et al. 2006) were used to calculate the toxicity equivalents (TEQs) of the PCDD/Fs and dl-PCBs. The range of the total TEQ values (sum of the

Table 2 Correlations of pollutant contents with total organic carbon in the Yellow and Yangtze rivers

\begin{tabular}{|c|c|c|c|c|c|c|c|}
\hline & & & TOC & $\mathrm{PCDD} / \mathrm{Fs}$ & dl-PCB & PCDD/Fs TEQ & dl-PCB TEQ \\
\hline \multirow[t]{3}{*}{ Yellow River } & TOC & Spearman Correlation & 1 & 0.140 & $0.635^{\mathrm{a}}$ & 0.230 & 0.319 \\
\hline & & Sig. (2-tailed) & & 0.648 & 0.020 & 0.450 & 0.289 \\
\hline & & $N$ & 13 & 13 & 13 & 13 & 13 \\
\hline \multirow[t]{3}{*}{ Yangtze River } & TOC & Spearman Correlation & 1 & -0.181 & 0.357 & -0.058 & 0.006 \\
\hline & & Sig. (2-tailed) & & 0.553 & 0.231 & 0.851 & 0.986 \\
\hline & & $N$ & 13 & 13 & 13 & 13 & 13 \\
\hline
\end{tabular}

${ }^{\text {a }}$ Correlation is significant at the 0.05 significance level (two-tailed) 
$\mathrm{PCDD} / \mathrm{F}$ and dl-PCB TEQs) in sediment samples from the Yellow River was $0.08-0.57 \mathrm{pg}$ WHO-TEQ/g dw. For all samples, the PCDD/F TEQ values ranged from 0.08 to $0.55 \mathrm{pg}$ WHO-TEQ/g dw and accounted for 73.6 to $99.3 \%$ of the total TEQ. The dl-PCB TEQ values ranged from 0.001 to $0.043 \mathrm{pg}$ WHO-TEQ/g dw and contributed to 0.7 to $26.4 \%$ of the total TEQ. The total TEQ values from the middle reaches of the Yellow River were comparable to those $(0.11$ to $1.01 \mathrm{pg}$ WHO-TEQ/g dw) reported for the Yellow Estuary (Hui et al. 2009), much lower than those (0.30-3319 pg WHO-TEQ $/ \mathrm{g} \mathrm{dw}$ ) from the lower reaches of the Haihe River basin in China (Li et al. 2013) and lower than those reported in the rivers in China and other countries (Table 1).

The range of the total TEQ values in the sediment samples from the Yangtze River was 0.092-0.474 pg WHO-TEQ/g dw (average $0.223 \mathrm{pg} \mathrm{WHO}-\mathrm{TEQ} / \mathrm{g} \mathrm{dw}$ ), which was similar to that in the Yellow River in this study. The PCDD/F-TEQ values (range $0.09-0.46 \mathrm{pg}$ WHO-TEQ/g dw) contributed to 87.8 to $98.4 \%$ of the total TEQ values. The dl-PCB TEQ values ranged from 0.002 to $0.036 \mathrm{pg}$ WHO-TEQ $/ \mathrm{g} \mathrm{dw}$ and only contributed to 1.6 to $12.2 \%$ of the total TEQ. The contents of PCDD/Fs and dl-PCBs in the middle reaches of the Yangtze River in China were much lower than or equal to those reported in other rivers in China and in other countries (Table 1).

Overall, the contribution rates of the PCDD/Fs TEQs to the total TEQs in both rivers were higher than those of the dlPCBs TEQs. These findings imply that toxic effects in these regions will mainly come from PCDD/Fs.

\section{Correlation analysis with TOC}

The correlation among PCDD/Fs, dl-PCBs, and TOC in sediments from the Yellow and Yangtze rivers was investigated, and the results are shown in Table 2. Organic matter in sediments is the principal factor controlling the sorption of organic compounds (Cornelissen et al. 2005). PCDD/Fs and dl-PCBs are lipophilic organic compounds and TOC reflects the amount of organic matter; therefore, TOC might be significantly correlated with $\mathrm{PCDD} / \mathrm{F}$ and $\mathrm{dl}-\mathrm{PCB}$ content in sediments. TOC was strongly correlated $(p<0.001)$ with $\mathrm{PCBs}$ and co-PCBs, but less so with PCDD/Fs $(p<0.05)$ in European background soils (Nam et al. 2008). For PCDD/Fs, the concentrations were significantly correlated with suspended particulate matter, while no correlation to TOC was observed. In the estuary and sea, PCB concentrations were correlated with TOC (Josefsson et al. 2011).

The TOC in the Yellow River sediments ranged from 2.10-19.20 g/kg, which was higher than that previously reported in Yangtze River sediments (Bouloubassi et al. 2001; Wen et al. 2008). TOC and dl-PCB contents were significantly correlated (Spearman's correlation coefficient, $r=0.64, P<0.05$ ), implying that organic carbon is an important factor governing the transport and distribution of dl-PCB in the Yellow River. In the Yangtze River, the TOC range was $8.80-33.60 \mathrm{~g} / \mathrm{kg}$. There was no significant correlation between the TOC and dl-PCB levels at the 0.05 significance level (Spearman's correlation coefficient, $r=0.36, P=0.23$ ). TOC is one of the possible factors affecting the migration and distribution of PCBs.

In the Yellow and Yangtze rivers, there was no significant correlation between TOC and PCDD/F contents, indicating that $\mathrm{PCDD} / \mathrm{F}$ contents might be affected by direct anthropogenic inputs.

\section{Distribution of PCDD/Fs and dl-PCBs}

The distributions of PCDD/Fs and dl-PCBs in surface sediments from the middle reaches of the Yellow and Yangtze rivers in China are shown in Fig. 2.

In the Yellow River, the highest PCDD/F-TEQ content was measured at site Y6 (0.55 pg WHO-TEQ/g), while the lowest
Fig. 2 Distribution of polychlorinated dibenzodioxins and dibenzofuran $(\mathrm{PCDD} / \mathrm{F})$ and dioxin-like polychlorinated biphenyl (dl-PCB) toxic equivalents in surface sediments from the middle reaches of the Yellow and Yangtze rivers

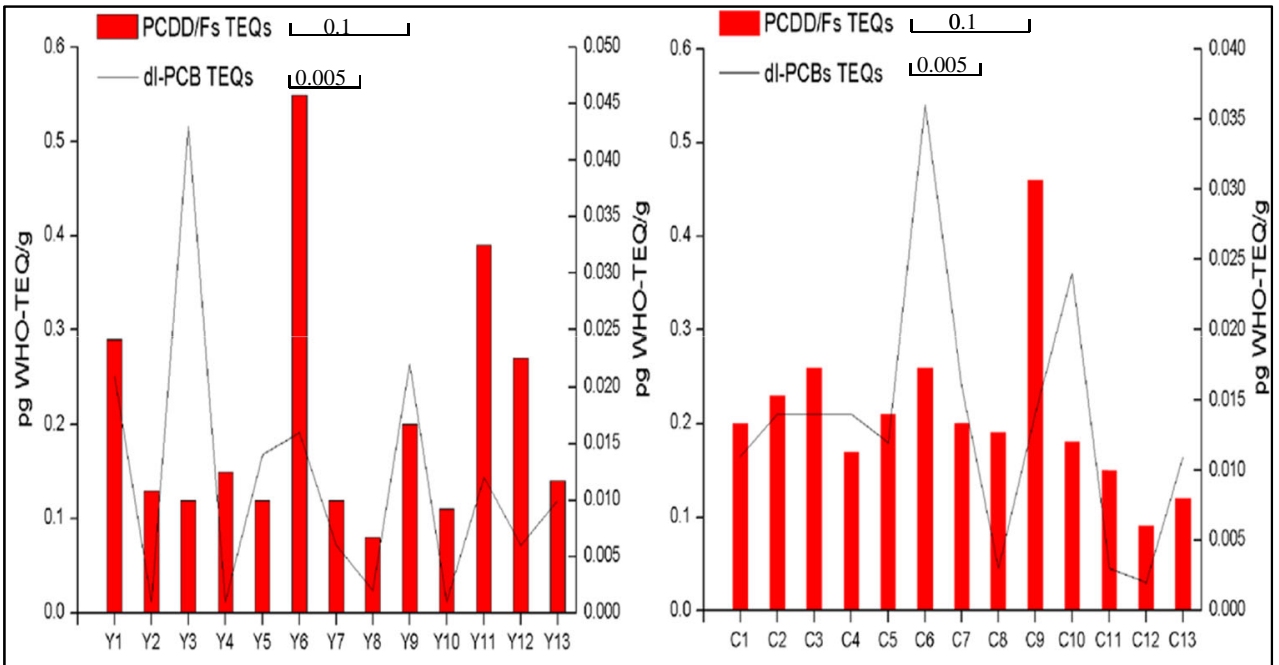


was at site Y8 (0.08 pg WHO-TEQ/g). During industrialization in the 1980s, many chemical plants, thermal power plants, and paper mills were established around Y6 and discharged sewage into the Yellow River without restraint. Additionally, there is still a carton plant in Huayuankou. Therefore, the PCDD/FTEQ content was very high along this stretch. A similar trend was observed in the Yi Luo River, where PCDD/F-TEQ contents in the lower reaches were higher than those in the upper reaches [content order: Y11 (0.39 pg WHO-TEQ/g) > Y12 (0.27 pg WHO-TEQ/g)>Y13 (0.14 pg WHO-TEQ/g)]. Distribution of dl-PCB differed from that of PCDD/Fs. Compared with other sampling locations, the PCDD/F-TEQ content (0.12 pg WHO-TEQ/g) at site Y3 was low, but dl-PCB-TEQ content $(0.043 \mathrm{pg}$ WHO-TEQ/g) at site $\mathrm{Y} 3$ was more than twice that at the other sampling locations. Y3 is located below the wastewater outfall of a petrochemical plant at Luoyang, China, and industrial wastewater discharged by this plant may be a major source of dl-PCBs at this site. This hypothesis is consistent with the fact that the dl-PCB-TEQ content ( $0.001 \mathrm{pg} \mathrm{WHO}-\mathrm{TEQ} / \mathrm{g})$ at site Y2, which was located above the wastewater outfall, was lower than that at Y3 $(0.043 \mathrm{pg}$ WHO-TEQ/g).

In the Yangtze River, the highest PCDD/F-TEQ content was detected at site $\mathrm{C} 9(0.46 \mathrm{pg}$ WHO-TEQ/g), followed by C3 (0.26 pg WHO-TEQ/g). There are numerous fertilizer plants, cement factories, tea farms, and printing and manufacturing plants located above $\mathrm{C}$, which would all produce pollution and contribute to the higher PCDD/F content at C9 than at the other sites. Because these factories are all relatively small, the PCDD/F content in $\mathrm{C} 9$ was lower than those reported in the rivers in China and other countries (Table 1). The highest dl-PCB-TEQ content was found at site C6 (0.036 pg WHO-TEQ/g), followed by C10 (0.024 pg WHO$\mathrm{TEQ} / \mathrm{g})$.

\section{Sources of PCDD/Fs and dl-PCBs in sediments}

The congener profiles of PCDD/Fs at the various sampling sites from the Yellow and Yangtze rivers were similar. The dominant congeners were octachlorodibenzo- $p$-dioxin (OCDD), followed by octachlorodibenzofuran (OCDF), 1,2, 3,4,6,7,8-heptachlorodibenzo- $p$-dioxin $(1,2,3,4,6,7,8$ HpCDD), and 1,2,3,4,6,7,8-heptachlorinateddibenzofuran (1, $2,3,4,6,7,8-\mathrm{HpCDF})$. These findings indicate that the pollution may be from impurities in organochlorine pesticides, such as sodium pentachlorophenate (Na-PCP) and pentachlorophenol (PCP), used in China. The dominant congeners of PCDD/Fs from atmospheric deposition (Ren et al. 2007) were OCDD, 1,2,3,4,6,7,8-HpCDD and 1,2,3,4,6,7,8-HpCDF, indicating that the PCDD/Fs contamination in the Yellow and Yangtze rivers might arise from atmospheric deposition. To further confirm the pollution sources, PCA was conducted for $17 \mathrm{PCDD} / \mathrm{F}$ congeners in the sediment samples. Results for the Yellow River are shown in Fig. 3a, and those for the Yangtze River in Fig. 3b.

For the Yellow River, PCA (Fig. 3a) indicated that PC1 accounted for $89.8 \%$ and PC2 accounted for $6.4 \%$ of the total variability. Therefore, most of the variation in the PCDD/Fs data set could be explained by the first two components. In the score plot, samples Y1-Y11 appeared to cluster together with PCP (Bao et al. 1995), Na-PCP (Bao et al. 1995), and atmospheric deposition (Ren et al. 2007). Y13 was located close to some municipal solid waste incinerators (Shih et al. 2006). The Y12 data point was separated from the other points by a high level of OCDF. The PCDD/F pollution at site Y12 might originate from mixed sources, including thermal electricity generation and wastewater discharges from ferries. None of the sampling sites clustered with an aluminum smelter (Li et al. 2007). PCA of samples from the Yangtze River (Fig. 3b) showed that PC1 and PC2 accounted for $98.3 \%$ of the total variability among samples (PC1, $95.5 \%$; $\mathrm{PC} 2,2.8 \%$ ). In the score plot, samples $\mathrm{C} 1-\mathrm{C} 9$ and $\mathrm{C} 11-\mathrm{C} 13$ appeared to cluster together with PCP, Na-PCP, and atmospheric deposition. The PCDD/F pollution at site C10 might originate from other sources. Figure $3 \mathrm{a}, \mathrm{b}$ suggests that PCP or Na-PCP use and atmospheric deposition are the main sources of PCDD/Fs in sediments in the Yellow and Yangtze rivers. Municipal solid waste incinerators could be a source of PCDD/F for the Yellow River, but not for the Yangtze River.

For dl-PCBs, the dominant congeners suggested that pollution in the Yellow and Yangtze rivers originated from coal and wood burning for domestic heating (Lee et al. 2005). Lower chlorinated congeners (CB77, CB118, and CB105) were dominant for the dl-PCBs, while the contents of high chlorinated congeners were substantially lower. Thus, dlPCBs in the two rivers may have been derived from use or production of Chinese technical products \#1PCB (CTP1) and Chinese technical products \#2PCB (CTP2) (Jiang et al. 1997). After production and use of these products ceased, new sources of PCBs arose, including electric and electronic waste (Stone 2009). Steel sinter plants (SSP) involve a number of high temperature processes (Aries et al. 2004) that increase the possibility of formation of trace amounts of dioxins (PCDDs, PCDFs, PCBs).

PCA was conducted for 12 dl-PCB congeners in the sediment samples and suspected PCB sources. The results are shown in Fig. 3c for the Yellow River and Fig. 3d for the Yangtze River. For the Yellow River, PC1 accounted for $78.3 \%$, and PC2 accounted for $11.9 \%$ of total variability. At least two clusters were identified in the score plots. Most samples were grouped with cluster 1 and were separated from CTP1 and CTP2. Y10 was grouped with CTP1 in cluster 2. Therefore, for most samples, dl-PCBs contamination was not correlated with the use and production of CTP1 and CTP2. Based on their proximity in the PCA score plot, domestic coal and wood were the main 

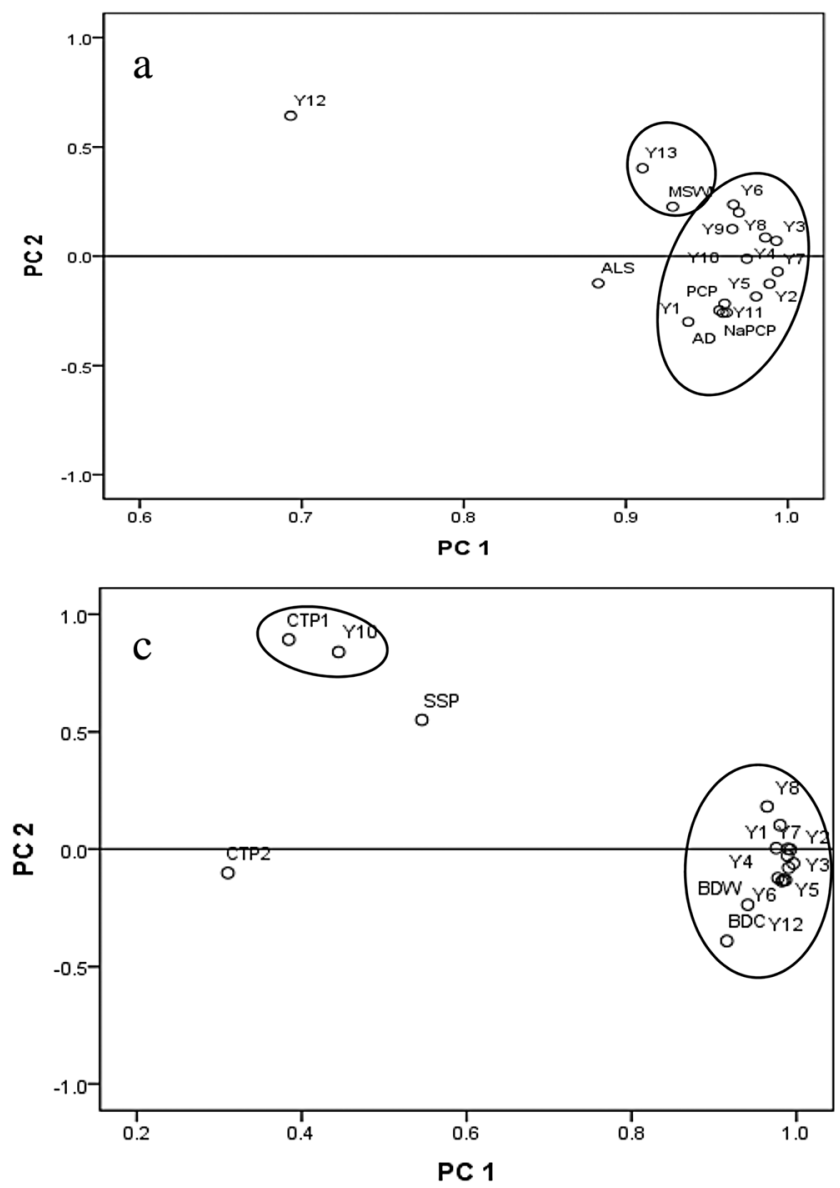

Fig. 3 Principal component analysis score plot of the PCDD/Fs and dlPCBs in sediment samples from the Yellow and Yangtze rivers. a PCA score plot of the PCDD/Fs in sediment samples from the Yellow River. $\mathbf{b}$ PCA score plot of the PCDD/Fs in sediment samples from the Yangtze River. c PCA score plot of the dl-PCBs in sediment samples from the Yellow River. d PCA score plot of the dl-PCBs in sediment samples from

sources of PCBs. For the Yangtze River, PC1 accounted for $77.0 \%$, and $\mathrm{PC} 2$ accounted for $9.0 \%$ of total variability. $\mathrm{C} 11$ was grouped with CTP2 in cluster 2. In addition to $\mathrm{C} 11$, the other samples were grouped in cluster 1 and were separated from CTP1, CTP2, and SSP, indicating that burning of domestic coal and wood was the main sources of dl-PCBs. Figure 3c, d suggested that burning of coal and wood for domestic heating were the main dl-PCB sources for sediment samples for the Yellow and Yangtze rivers.

\section{Risk assessment of PCDD/Fs and dl-PCBs}

The potential risk posed by PCDD/Fs and PCBs was evaluated using Canadian environmental quality guidelines for freshwater sediments (Environment 2001). These guidelines include the interim sediment quality guidelines (ISQG) and probable effect levels (PEL). The ISQG is the chemical content below which an adverse effect would rarely be observed, whereas the PEL is the content above which an


the Yangtze River. AD: atmospheric deposition, MSWI: municipal solid waste incinerators, ALS: aluminum ingot 9 smelter, BDC: burning of coal for domestic heating, BDW: burning of wood for domestic heating, CTP1: Chinese technical product \#1PCB, CTP2: Chinese technical product \#2PCB, SSP: steel sinter plant

adverse effect would be expected to occur frequently. The ISQG and PEL for PCDD/Fs, based on the tetrachlorodibenzo- $p$-dioxin (TCDD) toxicity equivalents, were 0.85 and $21.50 \mathrm{ng} \mathrm{TEQ} / \mathrm{kg} \mathrm{dw}$, respectively. Additionally, the ISQG and PEL for total PCBs were 21.5 and $189 \mu \mathrm{g} / \mathrm{kg}$, respectively.

The PCDD/F TEQ values from the Yellow River ranged from 0.08 to $0.55 \mathrm{pg} \mathrm{TEQ} / \mathrm{g} \mathrm{dw}$, which were lower than the ISQG. The PCDD/F TEQ values in the Yangtze River ranged from 0.09 to $0.47 \mathrm{pg} \mathrm{WHO-TEQ/g} \mathrm{dw,} \mathrm{which} \mathrm{were} \mathrm{also} \mathrm{lower}$ than the ISQG. The content of dl-PCBs in sediments from the Yellow and Yangtze rivers ranged from 1.1 to 9.9 and 1.8 to $24.1 \mathrm{pg} / \mathrm{g}$, respectively, which were much lower than the ISQG and the PEL. These results indicate that contamination of the middle reaches of these rivers is relatively low based on the aforementioned standard (Environment 2001). However, in view of future economic development and tightening environmental standards, further investigation of sediments, water, and animal species should be carried out in the future. 


\section{Conclusions}

Dioxins were detected in sediments from the middle reach of the Yangtze and Yellow rivers. The dominant congeners of $\Sigma_{17}$ PCDD/Fs were OCDD, OCDF, 1,2,3,4,6,7,8-HpCDD, and 1,2,3,4,6,7,8-HpCDF. Lower chlorinated congeners (CB77, CB118, and CB105) dominated the dl-PCBs. The levels of PCDD/Fs and dl-PCBs in the Yangtze River sediments were higher than those in the Yellow River sediments. Compared with Canadian environmental quality guidelines and the contents in other rivers in China and other countries, $\mathrm{PCDD} / \mathrm{F}$ and dl-PCB contents in both rivers were relatively low. Additionally, the TOC and dl-PCB contents in the Yellow River were significantly correlated, but there was no significant correlation between TOC and PCDD/F content in the Yellow and Yangtze rivers. TOC may be influencing the migration and distribution of $\mathrm{PCBs}$, while $\mathrm{PCDD} / \mathrm{F}$ contents might be influenced by direct anthropogenic inputs. PCA indicated that the potential main sources of PCDD/Fs were PCP, Na-PCP, and atmospheric deposition. PCA of the dl-PCBs profiles suggested that burning of domestic coal and wood was the main sources. The results presented herein advance our knowledge regarding eco-toxicity, provide useful information regarding contamination sources, and provide baseline data for future environmental risk assessments in the study area. Although assessment showed that the risk was low for these pollutants, the rapid development of the Chinese economy could create new sources of pollution. Therefore, regular monitoring of dioxins in this region is important.

Acknowledgments This research was funded by the National Natural Science Foundation of China (nos. 21377140 and 21321004).

\section{References}

Aries E, Anderson DR, Ordsmith N, Hall K, Fisher R (2004) Development and validation of a method for analysis of "dioxinlike" PCBs in environmental samples from the steel industry. Chemosphere 54:23-31. doi:10.1016/s0045-6535(03)00762-8

Bao Z, Wang K, Kang J, Zhao L (1995) Analysis of polychlorinated dibenzo-p-dioxins and polychlorinated dibenzofurans in pentachlorophenol and sodium pentachlorophenate. Chinese Journal of Environmental Chemistry 14:317-321

Bouloubassi I, Fillaux J, Saliot A (2001) Hydrocarbons in surface sediments from the Changjiang (Yangtze river) estuary, East China Sea. Mar Pollut Bull 42:1335-1346

Buckley-Golder D (1999) Compilation of EU Dioxins Exposure and Health Data, Summary Report for European Commission DG Environment and the UK Department of the Environmental Transport and the Regions. AEAT/EEQC/0016. http://ec.europa. eu/environment/archives/dioxin/pdf/dioxin.pdf

Castro-Jimenez J et al (2008) Atmospheric input of POPs into Lake Maggiore (Northern Italy): PCDD/F and dioxin-like PCB profiles and fluxes in the atmosphere and aquatic system. Chemosphere 73: S122-S130. doi:10.1016/j.chemosphere.2007.06.097
Cornelissen G, Gustafsson Ö, Bucheli TD, Jonker MT, Koelmans AA, van Noort PC (2005) Extensive sorption of organic compounds to black carbon, coal, and kerogen in sediments and soils: mechanisms and consequences for distribution, bioaccumulation, and biodegradation. Environ Sci Technol 39:6881-6895. doi:10.1021/es050191b

Da C, Liu G, Tang Q, Liu J (2013) Distribution, sources, and ecological risks of organochlorine pesticides in surface sediments from the Yellow River Estuary, China. Environ Sci-Proc Imp 15:22882296. doi:10.1039/c3em00369h

Eljarrat E, Caixach J, Rivera J, de Torres M, Ginebreda A (2001) Toxic potency assessment of non-and mono-ortho PCBs, PCDDs, PCDFs, and PAHs in northwest Mediterranean sediments (Catalonia, Spain). Environ Sci Technol 35:3589-3594. doi:10.1021/es010041a

El-Kady AA, Abdel-Wahhab MA, Henkelmann B, Belal MH, Morsi MK, Galal SM, Schramm KW (2007) Polychlorinated biphenyl, polychlorinated dibenzo-p-dioxin and polychlorinated dibenzofuran residues in sediments and fish of the River Nile in the Cairo region. Chemosphere 68:1660-1668. doi:10.1016/j.chemosphere.2007.03. 066

Environment CCOMOT (2001) Canadian Sediment Quality Guidelines for the Protection of Aquatic Life: Summary Tables. Canadian Environmental Quality Guidelines, 1999. Canadian Council of Ministers of the Environment Winnipeg. https://www.elaw.org/ system/files/sediment_summary_table.pdf

Fattore E, Viganò L, Mariani G, Guzzi A, Benfenati E, Fanelli R (2002) Polychlorinated dibenzo-p-dioxins and dibenzofurans in River Po sediments. Chemosphere 49:749-754

Gui Z-f, Xue B, Yao S-c, Wei W-j, Yi S (2012) Organic carbon burial in lake sediments in the middle and lower reaches of the Yangtze River Basin, China. Hydrobiologia 710:143-156. doi:10.1007/s10750012-1365-9

He MC, Sun Y, Li XR, Yang ZF (2006) Distribution patterns of nitrobenzenes and polychlorinated biphenyls in water, suspended particulate matter and sediment from mid- and down-stream of the Yellow River (China). Chemosphere 65:365-374. doi:10.1016/j. chemosphere.2006.02.033

Hosomi M, Matsuo T, Dobashi S, Katou S, Abe H (2003) Survey of dioxins in Tokyo Bay bottom sediment. Mar Pollut Bull 47:68-73. doi:10.1016/s0025-326x(02)00417-4

Hui Y, Zheng M, Liu Z, Gao L (2009) PCDD/Fs and dioxin-like PCBs in sediments from Yellow Estuary and Yangtze Estuary, China. B Environ Contam Tox 83:614-619. doi:10.1007/s00128-009-9832-3

Jiang K, Li L, Chen Y, Jin J (1997) Determination of PCDD/Fs and dioxin-like PCBs in Chinese commercial PCBs and emissions from a testing PCB incinerator. Chemosphere 34:941-950

Josefsson S, Karlsson OM, Malmaeus JM, Cornelissen G, Wiberg K (2011) Structure-related distribution of PCDD/Fs, PCBs and HCB in a river-sea system. Chemosphere 83:85-94. doi:10.1016/j. chemosphere.2011.01.019

Kannan K, Ramu K, Kajiwara N, Sinha RK, Tanabe S (2005) Organochlorine pesticides, polychlorinated biphenyls, and polybrominated diphenyl ethers in Irrawaddy dolphins from India. Arch Environ Con Tox 49:415-420. doi:10.1007/s00244-0057078-6

Kim KS et al (2009) Survey on organochlorine pesticides, PCDD/Fs, dioxin-like PCBs and HCB in sediments from the Han river, Korea. Chemosphere 75:580-587. doi:10.1016/j.chemosphere. 2009.01.075

Koh CH, Khim JS, Kannan K, Villeneuve DL, Senthilkumar K, Giesy JP (2004) Polychlorinated dibenzo-p-dioxins (PCDDs), dibenzofurans (PCDFs), biphenyls (PCBs), and polycyclic aromatic hydrocarbons (PAHs) and 2,3,7,8-TCDD equivalents (TEQs) in sediment from the Hyeongsan River, Korea. Environ Pollut 132:489-501. doi:10. 1016/j.envpol.2004.05.001

Lee RG, Coleman P, Jones JL, Jones KC, Lohmann R (2005) Emission factors and importance of PCDD/Fs, PCBs, PCNs, PAHs and PM10 
from the domestic burning of coal and wood in the UK. Environ Sci Technol 39:1436-1447. doi:10.1021/es048745i

Li C, Zheng M, Gao L, Zhang B, Liu L, Xiao K (2013) Levels and distribution of $\mathrm{PCDD} / \mathrm{Fs}$, dl-PCBs, and organochlorine pesticides in sediments from the lower reaches of the Haihe River basin, China. Environ Monit Assess 185:1175-1187. doi:10.1007/ s10661-012-2624-y

Li H-W, Lee W-J, Huang K-L, Chang-Chien G-P (2007) Effect of raw materials on emissions of polychlorinated dibenzo-p-dioxins and dibenzofurans from the stack flue gases of secondary aluminum smelters. J Hazard Mater 147:776-784. doi:10.1016/j.jhazmat. 2007.01.078

Liu M, Yang Y, Hou L, Xu S, Ou D, Zhang B, Liu Q (2003) Chlorinated organic contaminants in surface sediments from the Yangtze Estuary and nearby coastal areas, China. Mar Pollut Bull 46:672-676. doi: 10.1016/s0025-326x(03)000500-x

Montuori P, Cirillo T, Fasano E, Nardone A, Esposito F, Triassi M (2014) Spatial distribution and partitioning of polychlorinated biphenyl and organochlorine pesticide in water and sediment from Sarno River and Estuary, Southern Italy. Environ Sci Pollut R 21:5023-5035. doi: $10.1007 / \mathrm{s} 11356-013-2419-\mathrm{X}$

Nam JJ, Gustafsson O, Kurt-Karakus P, Breivik K, Steinnes E, Jones KC (2008) Relationships between organic matter, black carbon and persistent organic pollutants in European background soils: Implications for sources and environmental fate. Environ Pollut 156:809-817. doi:10.1016/j.envpol.2008.05.027

Neamtu M et al (2009) Chemical, biological, and ecotoxicological assessment of pesticides and persistent organic pollutants in the Bahlui River, Romania. Environ Sci Pollut R16:76-85. doi:10.1007/ s11356-009-0101-0

Nie Z et al (2013) Occurrence, possible sources, and temporal trends of polychlorinated dibenzo-p-dioxins and dibenzofurans in water and sediment from the lower Yangtze River basin, Jiangsu and Shanghai areas of Eastern China. Environ Sci Pollut R 20:8751-8762. doi:10. 1007/s11356-013-1832-5

Nunes M, Vernisseau A, Marchand P, Le Bizec B, Ramos F, Pardal MA (2014) Occurrence of PCDD/Fs and dioxin-like PCBs in superficial sediment of Portuguese estuaries. Environ Sci Pollut R 21:93969407. doi:10.1007/s11356-014-2891-y

Ren M, Peng P, Chen D, Chen P, Li X (2009) Patterns and sources of $\mathrm{PCDD} /$ Fs and dioxin-like PCBs in surface sediments from the East River, China. J Hazard Mater 170:473-478. doi:10.1016/j.jhazmat. 2009.04.072

Ren $\mathrm{M}$ et al (2007) Atmospheric deposition of polychlorinated dibenzop-dioxins and dibenzofurans (PCDD/Fs) in Guangzhou, China. Atmos Environ 41:592-605. doi:10.1016/j.atmosenv.2006.08.025
Sakai M, Seike N, Kobayashi J, Kajihara H, Takahashi Y (2008) Mass balance and long-term fate of PCDD/Fs in a lagoon sediment and paddy soil, Niigata, Japan. Environ Pollut 156:760-768. doi:10. 1016/j.envpol.2008.06.004

Shih SI, Wang YF, Chang JE, Jang JS, Kuo FL, Wang LC, Chang-Chien GP (2006) Comparisons of levels of polychlorinated dibenzo-p-dioxins/dibenzofurans in the surrounding environment and workplace of two municipal solid waste incinerators. J Hazard Mater 137: 1817-1830. doi:10.1016/j.jhazmat.2006.05.022

Song Y, Ji J, Mao C, Yang Z, Yuan X, Ayoko GA, Frost RL (2010) Heavy metal contamination in suspended solids of Changjiang River-environmental implications. Geoderma 159:286-295. doi:10.1016/j. geoderma.2010.07.020

Stone R (2009) Confronting a toxic blowback from the electronics trade. Science 325:1055-1055. http://www.kysq.org/docs/1055.pdf

Van den Berg M et al (2006) The 2005 World Health Organization reevaluation of human and Mammalian toxic equivalency factors for dioxins and dioxin-like compounds. Toxicol Sci 93:223-241. doi: 10.1093/toxsci/kfl055

Wang G-l, Ma L-m, Sun J-h, Zhang G (2010) Occurrence and distribution of organochlorine pesticides (DDT and $\mathrm{HCH}$ ) in sediments from the middle and lower reaches of the Yellow River, China. Environ Monit Assess 168:511-521. doi:10.1007/s10661-009-1131-2

Wen S, Hui Y, Yang F, Liu Z, Xu Y (2008) Polychlorinated dibenzo-pdioxins (PCDDs) and dibenzofurans (PCDFs) in surface sediment and bivalve from the Changjiang Estuary. Chin J Oceanol and Limn 26:35-44. doi:10.1007/s00343-008-0035-2

Wen Y, Yang Z, Xia X (2013) Dissolved and particulate zinc and nickel in the Yangtze River (China): distribution, sources and fluxes. Appl Geochem 31:199-208. doi:10.1016/j.apgeochem.2013.01.004

Yang H, Zhuo S, Xue B, Zhang C, Liu W (2012) Distribution, historical trends and inventories of polychlorinated biphenyls in sediments from Yangtze River Estuary and adjacent East China Sea. Environ Pollut 169:20-26. doi:10.1016/j.envpol.2012.05.003

Zhang $\mathrm{H}$ et al (2008) Polychlorinated dibenzo-p-dioxins and dibenzofurans in soils and sediments from Daliao River Basin, China. Chemosphere 73:1640-1648. doi:10.1016/j.chemosphere.2008.07. 067

Zhang Q, Jiang G (2005) Polychlorinated dibenzo-p-dioxins/furans and polychlorinated biphenyls in sediments and aquatic organisms from the Taihu Lake, China. Chemosphere 61:314-322. doi:10.1016/j. chemosphere.2005.02.099

Zhang S, Peng P, Huang W, Li X, Zhang G (2009) PCDD/PCDF pollution in soils and sediments from the Pearl River Delta of China. Chemosphere 75:1186-1195. doi:10.1016/j.chemosphere.2009.02. 032 